\title{
Monitoring ethical, legal, and social issues in developing population genetic databases
}

\author{
Melissa A. Austin, PhD, Sarah E. Harding, and Courtney E. McElroy
}

\begin{abstract}
Purpose: To characterize ethical, legal, and social issues unique to population genetic database research and to determine the relevance of international recommendations and guidelines for addressing these issues in the development of "genebank" projects globally. Methods: Building on our previous description of eight international genebanks, we conducted a comprehensive electronic search and literature review of relevant publications and consulted national and international documents applicable to genebank research. Results: We identified and characterized five categories of ethical, legal, and social issues unique to genebank development: sponsorship and benefit-sharing, neutrality and regulatory power of ethics committees, public engagement, consent, and data protection. We illustrate these issues with examples from specific genebanks. Not all of the issues are addressed in current international guidelines, many of which are nonspecific and unenforceable. Conclusion: The trend of genebank development promises to provide new discoveries to the field of medical science and to greatly improve public health. However, there is a growing need for more explicit, enforceable, and coordinated international guidelines relevant to the development and implementation of genebanks. By comparing ethical, legal and social issues as they arise in genebanks, researchers can better evaluate how to best use these projects to improve public health while protecting participating populations. Genet Med 2003:5(6):451-457.
\end{abstract}

Key Words: genetic databases, genebank, population genetics, genetics and ethics, public health genetics

The sequencing of the human genome has provided the international research community with a wealth of new information to use in further researching the role of genetic susceptibility in complex disease. ${ }^{1}$ However, maximizing the utilization of this information to benefit public health globally necessitates population-based knowledge regarding the frequency of susceptibility alleles, disease penetrance estimates, and the role of gene-environment interactions. ${ }^{2,3}$ To fulfill these goals, large regional populations are being recruited in many locations for the development of genetic databases. With the exception of the project in the Kingdom of Tonga, which was terminated due to ethical conflicts, development on all of these genetic databases has progressed significantly in the last year. These databases promise to further identify new genes that predispose individuals to common diseases, elucidate gene function, and improve public health by contributing to advances in medicine and pharmacogenomics.

We previously characterized population genetic databases, which we termed "genebanks" and defined them as "a stored collection of genetic samples in the form of blood or tissue, linked with medical and genealogical or lifestyle information

\footnotetext{
From Institute for Public Health Genetics, University of Washington, Seattle, Washington. Melissa A. Austin, PhD, Director, Institute for Public Health Genetics, 1959 N.E. Pacific Avenue, Box 357236, University of Washington, Seattle, WA 98195-7236.

Received: June 13, 2003.

Accepted: August 4, 2003.
}

DOI: 10.1097/01.GIM.0000093976.08649.1B from a specific population, gathered using a process of generalized consent." 4 Although consent for most genetic research is obtained for a specific disease and research agenda, genebank projects obtain "generalized consent" for an unspecified set of common diseases and for an undefined period of study. We earlier identified and described eight such project proposals that explicitly meet this definition; these are located in Iceland, the United Kingdom, Estonia, Latvia, Sweden, Singapore, Quebec, Canada, and the Kingdom of Tonga. These projects were proposed or begun with support from government and/or commercial organizations. We also identified two projects in the United States, located in Minnesota and Wisconsin, proposed by nonprofit medical clinics. The strategies used in all of these projects involve mapping susceptibility genes for complex diseases using linkage and/or association studies and studying variable responses to medical treatments for pharmacogenomic discovery.

While the characteristics of genebanks vary considerably, ${ }^{4}$ all raise similar ethical, legal, and social issues that need to be examined as the projects develop. In this study, we identify and examine five general categories of ethical, legal, and social issues (ELSI) in genebank development: genebank sponsorship and benefit-sharing, ethics committees, public engagement, consent, and data protection. We illustrate specific issues using examples from established and proposed genebank projects, and evaluate the relevance of guidelines and recommendations provided by various international and regional ethics bodies in addressing these issues. 


\section{METHODS AND RESULTS}

To identify ethical, legal, and social issues relevant and unique to genebank research, we undertook a comprehensive electronic search and literature review, using such search terms as biobank, genetic database, population genetics, and genetics and ethics, and terms specific to previously identified genebank projects. Documents reviewed include project and company Web sites, government documents, relevant news articles, and scientific and legal journal publications on the ethical, legal, and social issues in genetic research and health databases. Once the issues were identified, we consulted national and international policy documents that serve as relevant guidelines or recommendations for the conduct of governments and genetic researchers in constructing health databases. We identified thirteen relevant documents from eight organizations (see Table 1$)^{5-17}$ and applied these principles to ELSI issues that arise in genebank development and regulation. Whereas most of the policies were published within the last six years, we also included two well-established documents pertaining to research on human subjects: the Declaration of Helsinki ${ }^{5}$ and the Belmont Report. ${ }^{14}$

It is important to note that, with the exception of Council of Europe Conventions, ${ }^{9}$ none of these policies are legally enforceable. Furthermore, Council of Europe Conventions are only legally binding for those states that ratify them; ${ }^{18}$ of the present list of countries with proposed genebank projects, only Estonia has ratified the Council of Europe's Convention on $\mathrm{Hu}$ man Rights and Biomedicine. ${ }^{19}$

\section{Genebank sponsorship and benefit sharing}

Every genebank project involves varying levels of government and commercial support and some form of distributing the benefits of the research. For example, commercial companies with government approval and licensing initiated the De-
Code, UmanGenomics, and Autogen projects in Iceland, Sweden, and the Kingdom of Tonga, respectively. Government and commercial roles in genebank initiation and development each provoke specific concerns among project participants and observers regarding privacy and commercialization, and also lead to different mechanisms for distributing the potential benefits of research.

The role of the national government in several genebank projects raises unique concerns regarding the privacy of individual participants. The World Medical Association (WMA), in its 2002 Declaration on Ethical Considerations Regarding Health Databases, stated specifically that, "every precaution should be taken to respect the privacy of the subject."' However, the WMA leaves the idea of "every precaution" vague and undefined, and is therefore difficult to implement. Because no international privacy laws exist, the responsibility for protecting the privacy of individuals falls to national or regional governments. Therefore, the governmental sponsorship of some genebanks creates a conflict of interest between the government's interests in the success of the genebank and its responsibility to protect citizens and participants. In countries with socialized medicine, this could create fear that a government may attempt to reduce health care costs through practices such as withholding treatment from, or discouraging reproduction by, individuals with certain genetic traits. In the United Kingdom, Genewatch UK has organized opposition to Biobank UK focusing particularly on this issue. ${ }^{20}$

Commercial investment and involvement is often necessary in large-scale genetic database projects due to their large cost of development. However, financial gain by commercial investors raises objections to the commodification of a population's genetic heritage. ${ }^{21-23}$ Commodification in this context refers to the objectification of individuals and subordination of social value and self-constitution to market forces. ${ }^{24,25}$ Such objec-

Table 1

International guidelines for genebank research

\begin{tabular}{|c|c|}
\hline Advisory body & Guideline/recommendation \\
\hline \multirow[t]{2}{*}{ World Medical Association } & Declaration of Helsinki $(2000)^{5}$ \\
\hline & Declaration of Ethical Considerations regarding Health Databases $(2002)^{6}$ \\
\hline \multirow[t]{3}{*}{ Council of Europe } & Recommendation on IIuman Tissue Banks $(1994)^{7}$ \\
\hline & Recommendation on the Protection of Medical Data $(1997)^{8}$ \\
\hline & Convention on Human Rights and Biomedicine $(1997)^{9}$ \\
\hline \multirow[t]{2}{*}{ United Nations Educational, Scientific and Cultural Organization } & Draft Report on the Collection, Treatment, Storage and Use of Genetic Data (2001) ${ }^{10}$ \\
\hline & Declaration on the Human Genome and Human Rights $(1997)^{11}$ \\
\hline \multirow[t]{2}{*}{ Human Genome Organization Ethics Committee } & Statement on DNA Sampling: Control and Access $(1998)^{12}$ \\
\hline & Statement on Benefit Sharing $(2000)^{13}$ \\
\hline \multirow[t]{4}{*}{ Regional Ethics Guidelines } & The Belmont Report (1979) ${ }^{14}$ \\
\hline & Swedish Medical Research Council (1999)15 \\
\hline & Network of Applied Genetic Medicine (Quebec, Canada) (2000)16 \\
\hline & National Bioethics Advisory Committee (U.S.) (1999) ${ }^{17}$ \\
\hline
\end{tabular}


tions contributed to the failure of a proposed project in the Kingdom of Tonga. ${ }^{26}$ Although all of the ethical guidelines surveyed state clearly that genetic material should not be collected for the purposes of discrimination, the collection of samples for the purpose of financial gain is more ambiguous. Article four of the Declaration on the Human Genome and Human Rights states that the human genome should not give rise to financial gain in its natural state, ${ }^{11}$ but it is uncertain whether population genetic data constitutes the genome in its "natural state." Unfortunately, most references to this concept are vague; the Council of Europe states that "all of humanity" should enjoy the benefits of genetic research, and article 17 of the Universal Declaration of Human Rights states that all individuals have a right to property of which they cannot be arbitrarily deprived. ${ }^{9,27}$

In the funding of genebank projects, a conflict can arise between fair compensation for the organizations financially invested in projects and the participants, or "genetic donors." This issue is often referred to as "benefit sharing." 28 Although most international guidelines and recommendations for human genetic research allow for commercial pursuits, they maintain that benefits should be shared with participants in a fair manner. However, there are no means for legal enforcement of benefit sharing and no standard for what constitutes "fair" distribution of benefits. ${ }^{29}$ Some commercially funded genebank projects, such as deCode, UmanGenomics, and the Estonian Genome Project, pay a fee for use of the database information to the national Department of Health for improvement of health services. This arrangement follows the Council of Europe recommendation for benefit-sharing, stating, "parties, taking into account health needs and available resources, shall take appropriate measures with a view to providing, within their jurisdiction, equitable access to health care of appropriate quality." However, the guidelines do not include a definition of appropriate quality of care, and it is not clear that the payment of a fee to the health care system adequately compensates individuals of a population for their assumed risk in a genebank project. Additional conflicts of interest may arise regarding who determines this fee.

The benefits of research may also be shared by reporting results directly to participants to improve their medical services. As disease susceptibility genes are identified through population genetic research, the clinical utility of data within genebanks may compel the release of information. ${ }^{30}$ However, because result reporting to individual participants requires linking participant identity to data and samples, the maintenance of confidentiality within the genebank becomes more difficult. ${ }^{31}$ DeCode has chosen not to release information to Icelandic participants, but promises to provide pharmaceuticals that result from the research free of cost to the Icelandic population. ${ }^{32}$ At the Marshfield Clinic, new treatments resulting from database research will be published in periodic newsletters sent to participants. ${ }^{33}$ Plans for the Estonian Genome Project involve the release of genetic information to participants and their physicians for use in medical care. ${ }^{34}$ This, however, raises an additional issue, in that the release of genetic susceptibility information to participants may precede the availability of associated disease treatments as well as create additional risks, such as emotional and psychological harm. It may also result in increased health care costs for related services such as additional physician visits.

\section{Neutrality and regulatory power of ethics committees}

All of the identified genebank projects have associated ethics committees to oversee project development and to ensure that protocols for data collection and management are created with the welfare of potential participants in mind. However, the value of these committees depends on their neutrality and the amount of regulatory power they are delegated in project decision-making. Article 13 of the Declaration of Helsinki states that, "states should recognize the value of promoting, at various levels as appropriate, the establishment of independent, multidisciplinary and pluralistic ethics committees to assess the ethical, legal and social issues raised by research on the human genome and its applications." ${ }^{5}$ Ethics committees are charged, in principle, with protecting participants according to guidelines outlined in such international documents as the Universal Declaration on the Human Genome and Human Rights. ${ }^{11}$ At the Marshfield Clinic, an Ethics and Security Advisory Board was convened in order to guide the overall design of the Personalized Medicine Research Project on issues including confidentiality, nondisclosure of genetic analysis, and content of all major documents, especially the informed consent form. Biobank UK assembled an Ethics and Governance Interim Advisory Board to discuss ethics issues as the project develops and to advise the genebank sponsors on how to approach those issues. ${ }^{20}$

The neutrality of genebank ethics committees can be compromised by members' conflicts of interest or partiality in the appointment of members. For example, in Iceland, the Minister of Health stipulated that research conducted using genebanks would be overseen by a National Bioethics Committee, which would approve operational protocols in accordance with the Declaration of Helsinki. ${ }^{35}$ The formation of this committee has been criticized for a number of reasons. First, the original committee, which was critical of some aspects of the deCode project, such as the plan to use presumed consent, was replaced by one selected exclusively by government departments, rather than though external nominations. ${ }^{35}$ Also, several of the new committee members reportedly sit on the Scientific Board at deCode, Inc. ${ }^{36}$ Although guidelines and recommendations such as the Declaration of Helsinki address the need for independent and multidisciplinary ethics committees, they offer few standards by which the committees should be appointed and operated and, as evidenced by the Iceland example, they are not enforceable.

While genebank ethics committees are crucial for providing guidance and recommendations for progress on genebank activities, they often hold very little regulatory power over actual project development. A primary function of the committees is to interpret existing international guidelines and recommendations pertaining to genetic and health database research, 
many of which are nonspecific and unenforceable. Thus, beyond national laws, there is no oversight or accountability of these individual genebank ethics committees.

Because gene discovery within a population has implications beyond its study participants, current genebank ethics committees may not protect all of the individuals at risk from the research. For example, the identification of a trait within a population might lead to the mistaken conclusion that the trait originated in, or is more prevalent in, that study population or related populations in other locations, possibly resulting in discrimination and stigmatization. At present, no international supervisory body exists to protect all those at risk from population genebank research.

\section{Public engagement: Recruitment and education of participants}

Collecting the large number of samples necessary for genetic database research requires a significant recruitment effort and necessitates public awareness of the possible risks and benefits associated with participation in the genebank. Such awareness is required for concordance with international guidelines for consent. In its Draft Report on the Collection, Treatment, Storage, and Use of Genetic Data, the United Nations Educational, Scientific, and Cultural Organization (UNESCO) states that public education must give equal and unbiased mention of the risks and benefits involved in genetic research, while reaching a relatively large and, ideally, representative sample of the population..$^{10}$ In addition, recruitment protocols need to address the interests of the study population, and their particular concerns about genetic research. For example, some genebank recruitment materials emphasize the personal benefit that participants may expect or the economic benefits that might occur in the region due to increased employment opportunities. ${ }^{34}$ In another example, the Marshfield Clinic specifically notes that research studies will not be associated with such controversial topics as stem cell or cloning research, thereby anticipating study participants' concerns over how their information might be used. ${ }^{37}$ However, because genebank developers have a significant interest in recruiting as many members of the population as possible, a conflict arises when they are also charged with conducting an unbiased educational campaign.

For quality and effectiveness in public education, genebank developers must have an understanding of the culture of the population involved in the research and the groups' level of genetic comprehension. Two of the reasons for the cancellation of the Autogen Ltd. project in the Kingdom of Tonga, where no education in genetics is offered, were the questionable ability of the population to understand the implications of the proposed research and conflicts between the values inherent in the local culture and genetic technologies and research. ${ }^{26}$ Current guidelines and recommendations pertaining to genebank research offer very little practical guidance on the education of a participating population.

Physicians and health care professionals often play a role in recruitment and education efforts because they may be best suited for collecting samples and informing their patients about a genebank. For example, in Estonia, patients attending medical visits are invited to participate in the project by filling out extensive health questionnaires and donating blood samples. ${ }^{38}$ However, health practitioners may, even inadvertently, provoke a feeling of obligation among their patients to participate in genebank projects. Because many cultures have a paternalistic medical tradition, it may be difficult to ensure that informed consent is provided by a process in which individuals must choose not to participate in a project in the presence of an authority figure, their physician. ${ }^{39}$

An indirect, but still undeniable, form of coercion in recruitment took place in the deCode genetics project when individual Icelandic citizens invested financially in the company. DeCode's agreements with the Icelandic government involved a significant amount of investment in the company by the national banks. Bank officers then urged citizens to invest in deCode and a large marketing campaign also encouraged investment. ${ }^{40}$ The creation of this "gray market" in the country and considerable promotion of the stock compounded this situation and led a large proportion of the Icelandic population to become financially invested in deCode, Inc. Since this flurry of investing, which surrounded the passing of the Health Sector Database bill in 1998, the value of a single share in deCode has dropped from over US $\$ 60$ to less than US $\$ 5.40-42$ This deflation makes investors dependent on the project's future success for recouping their personal financial losses, which may make them feel obligated to participate in studies associated with the genebank.

\section{Informed, presumed, and community consent}

Consent is one of the most widely debated issues in the development of genetic databases. The World Medical Association Declaration of Helsinki gives a relatively concise and conclusive definition of informed consent:

In any research on human beings, each potential subject must be adequately informed of the aims, methods, sources of funding, any possible conflicts of interest, institutional affiliations of the researcher, the anticipated benefits and potential risks of the study and the discomfort it may entail. The subject should be informed of the right to abstain from participation in the study or to withdraw consent to participate at any time without reprisal. ${ }^{5}$

Active, informed consent is the generally accepted form of consent in most biomedical research, including genetic research. ${ }^{14}$ However, the scale of genebank research also necessitates community consultation and consent.

In contrast to the usual "opt-in" method of informed consent in genetic research, presumed consent occurs when representatives of a large community consents to research, requiring individuals to explicitly opt-out in order to be excluded. ${ }^{43}$ The directors of the deCode project in Iceland define presumed consent as "the consent of society to the use of health care information according to the norms of society." 32 The government of Iceland, in passing health database legislation, permitted the use of presumed consent for the collection of medical data and, in the Iceland Act on Biobanks, informed 
consent for the purpose of collecting genetic samples. ${ }^{44,45}$ The use of presumed consent provoked an international controversy and dissenting opinions from many legal and scientific experts. ${ }^{36}$ One scholar researching the project stated that the passage of the Icelandic legislation occurred with a "surprising lack of community consultation and public debate." 46 According to surveys, a majority of the Icelandic population supports deCode's research, although over 20 thousand people, or approximately seven percent of the population, have officially chosen not to participate. ${ }^{29,36,47}$

Because genebank research generally includes information on a large proportion of a population, and can involve risks to nonparticipating and nonconsenting members of a population, community consultation is essential and community consent needs to be considered. Both the UNESCO Draft Report on the Collection, Treatment, Storage and Use of Genetic Data and the Council of Europe Convention for the Protection of Human Rights and Biomedicine call for appropriate public consultation, beyond education and individual consent, in biomedical research. ${ }^{9,10}$ However, these guidelines differ on their definitions of community consent, as do research publications regarding the subject. The definition of community consent has ranged from informing the public of genebank activities to including public opinion in determining the course of genebank development. Because of ambiguity surrounding the concept of community consent, and because no official guidelines or recommendations on the topic exist, it is difficult for researchers and observers to determine whether appropriate objective standards have been met in the genebanks under development.

Other unique issues related to consent arise in genebank research. For example, appropriate methods of obtaining consent must be used when children and individuals who are without the mental capacity to legally consent to participate are included in genetic research. ${ }^{48}$ Because genebank developers seek to include large, diverse populations in their research, individuals with mental disabilities may not be afforded separate consent procedures, or may not be automatically excluded from presumed consent. Further, when samples and information have been previously collected, there is the potential for inclusion of data from deceased individuals, raising the question of whether consent is necessary for use of such information. ${ }^{15}$ Finally, the necessity of collecting family data for health histories and genealogy means that information regarding nonparticipating, and nonconsenting, members of the population might be included in the databases.

\section{Data protection: Confidentiality, data linkage, and data sharing}

Confidentiality procedures aim to ensure that information regarding participants is not disclosed without consent. ${ }^{49}$ In genebank projects, the linkage of different types of data, and the sharing of genebank data with third party researchers, can compromise measures of confidentiality. The Declaration of Helsinki, ${ }^{5}$ UNESCO, ${ }^{10,27}$ and the HUGO ethics committee ${ }^{12}$ all stress the importance of upholding confidentiality procedures: "every precaution should be taken to respect. . . the confiden- tiality of the patient's information." 5 In order to maintain confidentiality, information stored in genebanks is often "coded"4; that is, a unique identification number is attached to a sample to prevent information from being directly linked back to its donor. ${ }^{17}$ Because the success of each genebank is largely dependent upon the willingness of the targeted population to participate, the assurance of maintaining confidentiality is an important element in the success of the genebank.

Genebanks have taken a variety of measures to maintain confidentiality of information, and these have been met with different responses and criticisms. For example, at the Marshfield Clinic, research project coordinators obtained a Certificate of Confidentiality from the National Institutes of Health. This certificate prevents researchers from being forced to disclose information that may identify an individual, even with a court-ordered subpoena, in any federal, state, or local civil, criminal, administrative, legislative, or other proceedings. ${ }^{50}$ In addition, the coded data used in the Personalized Medicine Research Project is kept in a physically separate location, and on a different computer, from any other medical data at the Marshfield Clinic, and cannot be accessed on the Internet. ${ }^{50}$ In another example, critics of the deCode project believe Iceland's geographic isolation and limited number of kindred relationships may make it difficult, if not impossible, for deCode to maintain the privacy and confidentiality of personal information. ${ }^{31}$ Sample identification is of specific concern in smaller populations such as Iceland: "in a country with a relatively small population, information on genetics is likely to indicate biological lineage and to reveal identities of persons concerned." 31

Much of the utility of genebanks is derived from the linkage of genetic data, medical records and/or lifestyle information, and genealogical data for statistical calculations of disease risk. Data linkage in this context refers to combining several components of this information over time for an individual participant. While the potential for gene discovery using this approach is large, cross-linking various types of data increases the chances of identifying a participant and potentially violating confidentiality. ${ }^{31}$ Genebank projects that continuously add medical information to a database over time must take added precautions to ensure confidentiality. ${ }^{31}$ For example, in Biobank UK, participant medical records will be updated over at least 10 years so that researchers can prospectively track disease incidence over time. ${ }^{51}$ Although linking the medical records of a participant in this way may pose a risk to the individual's privacy, the resulting incidence data are often more valuable than prevalence data in understanding disease etiology. ${ }^{52}$

"Data sharing" refers to allowing third parties, such as independent academic researchers, access to genebank research data and results. Although many scholars argue that data derived in the development of genebanks ought to be freely available to all researchers to guarantee the rapid progress of medical research, the financial investment of genebank developers may create a reluctance to openly disclose data to outside researchers. ${ }^{53}$ The decision to share data also raises issues related to an individual participant's right to know what research is 
being conducted on his or her sample. The Council of Europe states that a participant ought to be informed of the purposes for which their data will be processed, as well as to whom their information may be communicated. ${ }^{8}$ The potential scientific value and ultimate social benefits of research resulting from collaboration among scientists must be weighed against the loss of control, or autonomy, of participants over their biological sample. ${ }^{54}$

For private genebank developers, such as deCode, datasharing strategies are designed to protect commercial interests. Legislation on the IHD (Icelandic Health care Database) grants power to a three-person committee, with members appointed by the government, the national university, and deCode, to determine access to genebank data, "provided that the research may not be expected, in the view of the committee, to have an adverse effect upon the licensee's commercial interests." 44 Proposals regarding data sharing in Biobank UK include requiring approval by an independent oversight committee. ${ }^{55}$ Additionally, researchers using the Biobank UK data are required to report their eventual findings to a central database in order to increase the speed of the progress of research and enhance the utility of the database. ${ }^{53,56}$

Data protection also involves the future use and storage of personal information within a genebank. Many international regulations, such as the Declaration of Helsinki, require that individuals maintain the right to withdraw their genetic sample from a database at any time. ${ }^{5,6,10}$ Different genebank projects, however, have varying requirements regarding the duration of storage and use of an individual's sample. For example, deCode's research protocol gives participants the choice of whether to participate in just one study, or in further studies that are yet to be disclosed. ${ }^{57}$ Participants can choose to withdraw from the research at any time, therefore preventing further information from entering the genebank; however, they cannot have data removed from the genebank once it is entered. ${ }^{57}$

\section{SUMMARY AND CONCLUSIONS}

Genebank development is the logical next step of gene discovery research after the sequencing of the human genome. ${ }^{58}$ However, research using national and regional populationbased genetic databases raises unique ethical, legal, and social issues that need to be examined. We have identified and characterized five categories of such issues: genebank sponsorship and benefit-sharing, neutrality and regulatory power of ethics committees, public engagement, consent, and data protection, not all of which are included in current international policy regulations and guidelines. In addition, existing policies are often nonspecific and not enforceable.

Thus, more empirical research examining specific issues, such as what constitutes a reasonable effort to protect privacy and the risks inherent in generalized consent, and a coordinated effort to develop comprehensive and widely applicable guidelines would be valuable. Although each genebank project provides its own mechanisms for protecting participants, the implications of genebank research extend well beyond national boundaries. Thus, as genebank projects progress, there is a growing need for more explicit, enforceable, and coordinated international policy guidelines. Several grassroots organizations, such as Mannvernd in Iceland and Genewatch in the UK, have manifested around specific local issues, but more coordinated advocacy on the international level would promote more effective policy development. Ideally, a global and independent advisory group would monitor the development of genebanks, assist in identifying potential issues as they arise, and generally ensure that genebank projects meet their goals of improving public health while protecting the participating populations.

\section{ACKNOWLEDGMENTS}

This work was supported by University Initiative Fund of the University of Washington and NIH grant P30ES07033 from NIEHS. The authors would like to thank Anna Mastroianni, Dr. Wylie Burke, Dr. Cindy Watts, Dr. Barbara Burns McGrath, and Dr. Kelly Fryer Edwards for editorial suggestions and technical support.

\section{References}

1. Venter JC, Adams MD, Myers EW, et al. The Sequence of the Human Genome. Science 2001;291:1304-1351.

2. Khoury M. Commentary: epidemiology and the continuum from genetic research to genetic testing. Am J Epidemiol 2002;156:297-299.

3. Beskow LM, Burke W, Merz JF, Barr PA, Terry S, Penchaszadeh VB, Gostin LO, Gwinn M, Khoury MJ. Informed consent for population-based research involving genetics. JAMA 2001;286:2315-2321.

4. Austin M, Harding S, McElroy C. Genebanks. A comparison of eight proposed international genetic databases. Community Genet 2003;6:37-45.

5. World Medical Association. Declaration of Helsinki: Ethical principles for medical research involving human subjects. J Postgrad Med 2002;48:206-208.

6. World Medical Association. Declaration on ethical considerations regarding health databases, adopted by WMA General Assembly, Washington DC, 2002.

7. Council of Europe. Recommendation No. R(94)1 of the Committee of Ministers to member states on human tissue banks, adopted by the Committee of Ministers at the 509th meeting of the Ministers' Deputies, 1994.

8. Council of Europe. Recommendation No. R(97) 5 of the Committee of Ministers to member states on the protection of medical data. Int Dig Health Legis 1998;49:502508.

9. Council of Europe. Convention for the protection of human rights and dignity of the human being with regard to the application of biology and medicine: convention on human rights and biomedicine. Int Dig Health Legis 1997;48:99-105.

10. United Nations Educational, Scientific, and Cultural Organization (UNESCO). Draft report on the collection, treatment, storage and use of genetic data, SHS-503/ 01/CIB-8/3, International Bioethics Committee, Paris 2001.

11. United Nations Educational, Scientific, and Cultural Organization (UNESCO). Declaration on the human genome and human rights, International Bioethics Committee, Paris 1997.

12. Human Genome Organization (HUGO) Ethics Committee. Statement on DNA sampling: control and access, London, 1998. Available at: http://www.gene.ucl.ac.uk/hugo/sampling.html. Accessed July 21, 2003.

13. Human Genome Organization (HUGO) Ethics Committee. Statement on benefitsharing, Vancouver 2000 Available at: http://www.hugo-international.org/hugo. Accessed July 21, 2003.

14. National Commission for the Protection of Human Subjects of Biomedical and Behavioral Research. The Belmont Report: ethical principles and guidelines for the protection of human subjects of research, Washington D.C. 1979.

15. Swedish Medical Research Council (MFR). Research ethics guidelines for using biobanks in genome research Dnr 1999-570, 1999. Available at: http://www.mfr.se/ filserver/index.asp?fil=J1SHVF2XTCCO. Accessed July 21, 2003.

16. Network of Applied Genetic Medicine (RMGA). Statement of principles: human genome research, 2000. Available at: http://www.rmga.qc.ca. Accessed July 21, 2003.

17. National Bioethics Advisory Committee. Research involving human biological materials: ethical issues and policy guidelines, 1999. Available at: http://www.georgetown.edu/research/nrcbl/nbac/pubs.html. Accessed July 21, 2003. 
18. Council of Europe. About conventions and agreements in the European Treaty Series (ETS), 2002. Available at: http://conventions.coe.int. Accessed July 21, 2003.

19. Council of Europe. Legal Affairs: Treaty Office, 2003. Available at: http://conventions.coe.int/treaty/EN/cadreprincipal.htm. Accessed July 21, 2003.

20. Genewatch UK. 2003. Available at: http://www.genewatch.org. Accessed July 21, 2003.

21. Kaiser J. Population databases boom, from Iceland to the U.S. Science 2002;298: $1158-1161$.

22. Lewontin R. People are not commodities. New York Times January 23, 1999:A19.

23. Brown B. The case for caution: Being protective of human dignity in the face of corporate forces taking title to our DNA. J Law Med Ethics 2001;29:166-169.

24. Cahill L. Genetics, commodification, and social justice in the globalization era. Kennedy Inst Ethics J 2001;11:221-238.

25. Radin M. Contested commodities. Cambridge, Mass: Harvard Univ. Press, 1996

26. Burton B. Proposed genetic database on Tongans opposed. BMJ 2002;324:443.

27. United Nations. Universal Declaration of Human Rights, Adopted by General Assembly 1948. Available at: http://www.un.org/Overview/rights.html. Accessed July 21, 2003.

28. Knoppers B. Population genetics and benefit sharing. Community Genet 2000;3: 212-214.

29. Palsson G, Rabinow P. The Icelandic genome debate. Trends Biotechnol 2001;19: $166-171$.

30. O'Leary LA, Collins DL. Using the Internet to disseminate genetics information for public health. New York: Oxford Press, 2000.

31. Anderson R. The deCode proposal for an Icelandic Health Database, 1998. Available at: http://www.ftp.cl.cam.ac.uk/ftp/users/rja14/iceland.pdf. Accessed July 21, 2003.

32. Gulcher J, Stefansson K. The Icelandic healthcare database and informed consent. N Engl J Med 2000;342:1827-1830.

33. Mitka M. Banking (on) Genes: DNA sought as key to disease causes and cures. JAMA 2002;288:2951-2952.

34. Estonian Genome Project Foundation. Tartu, Estonia: Estonian Genome Project, 2002.

35. Abbott A. 'Strengthened' Icelandic bioethics committee comes under fire. Nature 1999;400:602.

36. Mannvernd, Association of Icelanders for Ethics in Science, and Medicine. Conflict of interest in the National Bioethics Committee, 1999. Available at: http://www.mannvernd.is/english/news/hg.minister.html. Accessed July 21, 2003.

37. Marshfield Clinic. Personalized Medicine Research Project, 2003. Available at: http://www.mfldclin.edu/pmrp/. Accessed July 21, 2003.
38. Hollon T. Gene pool expeditions. Scientist 2001;15:1.

39. Frank L. Biotechnology in the Baltic. Nat Biotechnol 2001;19:513-515.

40. Johannesson V. Mere foolishness? Morgunblad September 13, 2002.

41. Meek J. Decode was meant to save lives...now it's destroying them. The Guardian, 2002. Available at: http://www.guardian.co.uk/g2/story/0,3604,822816,00.html. Accessed July 21, 2003.

42. Erlingsson S. Kari sleeps quietly like the boy Paul, 2001. Available at: http://www.raunvis.hi.is/ steindor/kari2.html. Accessed July 21, 2003.

43. Hauksson P. Icelanders opt out of genetic database. Nature 1999;400:707-708

44. Althingi. Bill on a Health Sector Database, 1999

45. Althingi. Act on Biobanks no. 110/2000, 2000.

46. Winickoff D. Context and content of Iceland's Biobank Act. J Biolaw Bus 2000;4:1117.

47. Rose H. The Commodification of Bioinformation: The Icelandic Health Sector Database. London: Wellcome Trust, 2001.

48. Annas G. Rules for research on human genetic variation: Lessons from Iceland N Engl J Med 2000;342:1830-1833

49. Andrews LB, Mehlman MJ, Rothstein MA. Genetics: ethics, law and policy, St. Paul, MN West Group 2002.

50. Marshfield Clinic. Personalized Medicine Research Project: Is there a risk to my confidentiality? 2003. Available at: http://www.mfldclin.edu/pmrp/pmrpprivate.asp. Accessed July 21, 2003.

51. Biobank UK. Protocol for the UK Biobank: A study of genes, environment and health, 2002. Available at: http://www.ukbiobank.ac.uk/documents/draft_protocol.pdf. Accessed July 21, 2003.

52. Gordis L. Epidemiology, 2nd ed. Philadelphia: W.B. Saunders Company, 2000

53. Staley K. Giving your genes to Biobank UK: Questions to ask, 2001. Available at: http://www.genewatch.org. Accessed July 21, 2003.

54. Cambon-Thomsen A. Assessing the impact of biobanks. Nat Genet 2003;34:25-26

55. The UK Biobank Ethics Consultation Workshop, 2002. Available at: http://www.ukbiobank.ac.uk/documents/ethics_work.pdf. Accessed July 21, 2003.

56. House of Lords Select Committee on Science, and Technology. Human Genetic Databases. Written Evidence, 2000.

57. DeCode Genetics. Informed consent document, 2002. Available at: http://www.decode.com/files/cache/files/

file40420.pdf?filecontent $=40420 \&$ filecontenttype $=$ application/pdf. Accessed July 21, 2003.

58. Collins FS, Green ED, Guttmacher AE, Guyer MS. A vision for the future of genomics research. Nature 2003;422:835-847. 